\title{
The effects of lemon verbena (Lippia citriodora) verbascoside on the productive performance, plasma oxidative status, and some blood metabolites in suckling lambs
}

\author{
D. Casamassima ${ }^{1,4}$, M. Palazzo ${ }^{1}$, A.G. D’Alessandro ${ }^{2}$, G.E. Colella ${ }^{1}$, F. Vizzarri' and C. Corino ${ }^{3}$ \\ ${ }^{1}$ University of Molise, Department of Agriculture, Environmental and Food, Via De Sanctis snc - 86100 Campobasso, Italy \\ 2 University of Bari, Department of Animal Production, Via Amendola 165/A - 70126 Bari, Italy \\ ${ }^{3}$ University of Milan, Department of Veterinary Science and Technologies for Food Safety \\ Via Celoria, 10 - 20133 Milano, Italy
}

KEY WORDS: blood parameters, Lippia citriodora, verbascoside, production performance, suckling lambs

Received: 2 August 2012

Revised: 31 May 2013

Accepted: 2 September 2013

${ }^{4}$ Corresponding author: e-mail:

casamassima.d@unimol.it

\begin{abstract}
The effects of two doses of a verbascoside-based dietary supplement on performance, some blood parameters, and plasma oxidative status in Lacaune suckling lambs were investigated. Twenty-four lambs were divided into three groups of eight animals each and fed peros a dietary supplement with a plant extract from Lippia citriodora containing a phenylpropanoid glycoside, verbascoside: the low-verbascoside (LVB) group received $2.5 \mathrm{mg}$ per animal per day of natural extract, the high-verbascoside (HVB) group received $5.0 \mathrm{mg}$ per animal per day, the control group (CON) did not receive dietary supplementation. The body weight, average daily gain, milk consumption and milk conversion index were determined for the experimental and control animals and blood samples were taken from all lambs. Dietary supplementation with verbascoside in both the LVB and HVB groups resulted in improved average daily gain $(P<0.01)$, milk consumption $(p<0.05)$, and serum lipid profile; the groups showed a decrease in triglycerides $(p<0.05)$ and an increase in high density lipoprotein cholesterol levels $(p<0.05)$. Plasma oxidative status in lambs supplemented with verbascoside showed an improvement in homoeostatic stability that induced a significant decrease in reactive oxygen metabolites $(P<0.01)$ and thiobarbituric acid-reactive substances $(p<0.05)$ concentrations and a marked increase in serum concentrations of vitamin $E(P<0.01)$ and vitamin $\mathrm{A}(p<0.05)$.
\end{abstract}

\section{Introduction}

Oxidative stress is a particular condition of an organism that is caused by an accentuation, in the pro-oxidant sense, of the dynamic balance between oxido-reduction processes occurring in the cell with the production of radical species (Sies, 1991). Many substances present in plants are able to neutralize the action of free radicals or to interrupt the chain reactions leading to their formation, thus inhibiting the propagation of cellular damage.

Amongst natural active compounds that have demonstrated antioxidant properties, verbascoside, a phenylpropanoid glycoside, is present in numerous medicinal plants and is called pseudo-ginseng by the populations of Northeast China. 
Many studies have shown that verbascoside has anti-inflammatory (Deepak and Handa, 2000; Marzocco et al., 2007; Esposito et al., 2010), antibacterial (Ellis, 1983), antiviral (Kernan et al., 1998), immunomodulatory (Akbay et al., 2002) and antioxidant (Corino et al., 2007a,b; Rossi et al., 2009; Palazzo et al., 2011) effects by providing a scavenger effect on reactive oxygen species (Gao et al., 1999).

In our previous research (Casamassima et al., 2011, 2012; Palazzo et al., 2011) on the brown hair rabbit, and dairy sheep using verbascoside as a dietary feed, a general improvement of blood lipid profiles, plasmatic oxidative status, in particular, significant decreases of reactive oxygen metabolites (ROMs) and thiobarbituric acid reactive substances (TBARS), and an increase of endogenous vitamin A and $\mathrm{E}$ reserves were noted. Also, a marked increase in the milk yield of ewes was demonstrated.

The antioxidative properties of plant extracts, which can also stimulate the appetite and positively affect the secretion of endogenous digestive enzymes and influence blood constituents, are particularly important for organisms (Lee et al., 1995; Grassmann et al., 2000; Yoshioka et al., 2000; Perucka and Materska, 2001).

The administration of dietary verbascoside-based feed in suckling lambs could be useful in minimizing some types of stress on digestive organs by protecting the gastrointestinal tract from colitis (Esposito et al., 2010).

The objective of this study was to assess the effects of two doses of a verbascoside-based dietary supplement on some blood parameters, plasma oxidative status, and productive performance of suckling lambs.

\section{Material and methods}

\section{Animals and diets}

All experimental procedures involving animals were in accordance with European Community guidelines and approved by the Italian Ministry of Health.

Lacaune male lambs $(n=24$; age $1-3$ days; born from single lambings, initial body weight $5.08 \pm 0.46 \mathrm{~kg}$ ) were weighed at the beginning of the trial, divided by body weight (BW), and randomly assigned to individual treatments $(\mathrm{n}=8$ per treatment). Throughout the trial lasting 42 days, the body health condition of the animals was good and the lambs received exclusively maternal milk. The ewes, intensively reared and multiparous, were fed on $1.8 \mathrm{~kg}$ of permanent meadow polyphyte hay: crude protein $(\mathrm{CP})-8.4 \%$, neutral detergent fibre (NDF) $-64.6 \%$, acid detergent fibre (ADF) $48.0 \%$, acid detergent lignin (ADL) $-6.7 \%$, ash $10.2 \%$ dry matter (DM), and $700 \mathrm{~g}$ of a concentrate mixture (G.I.Ma., Perugia, Italy) with the following chemical composition: $\mathrm{CP}-18.9 \%$, crude fibre $11.5 \%$, ether extract $-2.9 \%$, NDF $-13.8 \%$, ADF $-7.3 \%$, ADL $-1.5 \%$, ash $-2.5 \%$ DM.

The treatments differed in terms of the dose of administered verbascoside: $0,2.5$, or $5 \mathrm{mg}$ per animal per day (control group - CON, low-level verbascoside group - LVB, and high-level verbascoside group - HVB). An extract from Lippia citriodora leaves standardized to $20 \%(\mathrm{w} / \mathrm{w})$ of verbascoside (VB; Figure 1), was used (Mazzon et al., 2009). The antioxidant supplement was prepared on an industrial scale by a standardized procedure that includes ultrasonic extraction with $60 \%$ aqueous ethyl alcohol followed by spray-drying with maltodextrins as an excipient. Verbascoside is present in an amount over $80 \%(\mathrm{w} / \mathrm{w})$ of total phenylpropanoids, together with a minor mixture $(<10 \%)$ of other caffeic acid derivatives (from the certificate of analysis provided by the manufacturer, I.R.B. s.r.l., Altavilla Vicentina, Vicenza, Italy). This extract, in aqueous solution, was administered daily per os according to the experimental dosage at 9 a.m. by means of a dispenser equipped with an appropriate dispensing device (Pfizer Animal Health, Latina, Italy).

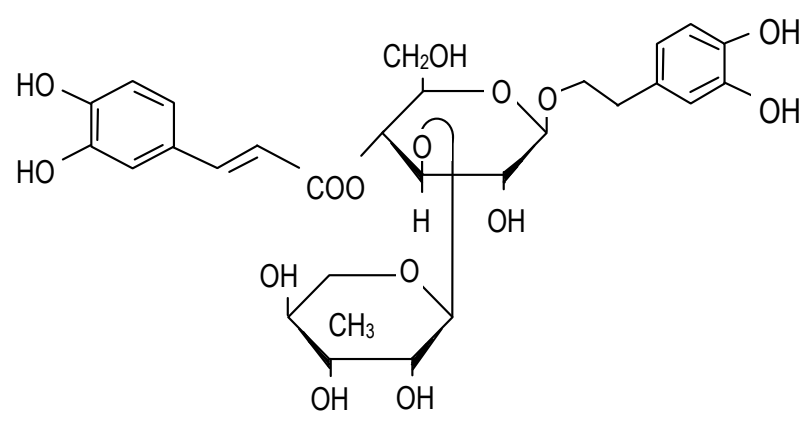

Figure 1. Chemical structure of verbascoside

During the trial, the lambs underwent the following experimental assessment: BW at $0,14,28$, 42 days, and average daily gain (ADG) in the periods of 0-14 d, 14-28 d and 28-42 d; after a twelvehour fast, blood samples were collected into a vacutainer from the external jugular vein on days 0 , 21 and 42; daily milk consumption, using the system of double weighing, on days $0,14,28$, and 42 was determined. On the control day, the lambs were kept away from their mothers for $24 \mathrm{~h}$, except for two one-hour suckling periods at 8 a.m. and 8 p.m. 
The lambs were weighed before and after each suckling period.

Daily milk consumption (between days $0-14$, 14-28 and 28-42) was reported as an average of the values between two consecutive control days. Daily milk consumption was used to calculate the milk conversion index in each interval period.

\section{Blood analysis}

Blood samples were stored in three vials: the first used a separating gel to produce serum, the second used lithium heparin to produce plasma, the third used EDTA for the haemochromocytometric test. Blood was centrifuged for $15 \mathrm{~min}$ at $2000 \mathrm{~g}$ and at room temperature and the serum was immediately tested for the following: triglycerides, total cholesterol, high-density lipoprotein cholesterol (HDL-C), low-density lipoprotein cholesterol (LDL-C), albumin, urea, creatinine and bilirubin using an automatic clinical chemistry analyzer, model ARCO (Biotecnica Instruments S.p.A., Italy). The concentration of ROMs in plasma was determined using a colorimetric method, as proposed by Diacron (Grosseto, Italy) and a specific commercial kit, absorbance was measured in a specrophotometer at a wavelength of $505 \mathrm{~nm}$ (Cesarone et al., 1999). The results are expressed in arbitrary units called 'Carratelli units' (Carr U) where 1 CARR corresponds to $0.024 \mathrm{mmol} \cdot 1^{-1}$ of $\mathrm{H}_{2} \mathrm{O}_{2}$.

Plasma TBARS were determined according to Esterbauer and Zollern (1989). Briefly, a standard curve was generated using 1,1,3,3-tetramethoxypropane (Sigma Aldrich, St. Louis). Trichloroacetic acid $(10 \% \mathrm{v} / \mathrm{v})$ was added to the plasma samples to precipitate proteins. The resulting mixture was incubated for $15 \mathrm{~min}$ on ice. After centrifugation at $2200 \mathrm{rpm}$ at $4^{\circ} \mathrm{C}$ for $15 \mathrm{~min}, 0.67 \%$ thiobarbituric acid was added to the supernatant. The mixture was incubated in a water bath at $90^{\circ} \mathrm{C}$ for $10 \mathrm{~min}$, after which the absorbance was read at $532 \mathrm{~nm}$ in a spectrophotometer. The results were expressed as $\mu \mathrm{mol}$ of thiobarbituric acid per litre of plasma.

Vitamins A and E were extracted from plasma samples with chloroform (Zhao et al., 2004) and analysed on an HPLC system (Kontron Instruments, Italy) consisting of an autosampler (HPLC Autosampler 360) with a $20 \mu 1$ loop, a high pressure mixing pump, and a $5 \mu \mathrm{m}, 250 \times 4.60 \mathrm{~mm} \mathrm{C} 18$ column (Phenomenex, Torrance, CA, USA). The mobile phase was nitrile acid and methanol (75:25 $\mathrm{v} / \mathrm{v}$ ) at a flow rate of $1.0 \mathrm{ml} \cdot \mathrm{min}^{-1}$. A fluorimeter detector (SFM) and computer with Kroma System
2000 software were used. The concentrations of vitamins $\mathrm{A}$ and $\mathrm{E}$ were determined using an internal standard and the elution time of pure standards.

Whole blood was tested for haematological parameters, including red blood cells (RBC), white blood cells (WBC), haemoglobin (HGB), haematocrit (HCT), mean corpuscular volume (MCV), mean corpuscular haemoglobin $(\mathrm{MCH})$, mean corpuscular haemoglobin concentration (MCHC), and platelets (PLT) using an automatic blood cell counter SEAC (Radim Company, Italy).

\section{Statistical analysis}

Analysis of variance was performed on all of the variables after the normality of the frequency distribution was assessed by the GLM procedure for repeated measurements of the SPSS statistical package (2010). Analysis included between-subjects main effect (D) of dietary supplementation (CON, LVB, and HVB), within-subjects main effect of sampling time $(\mathrm{T})$, and the interaction of dietary supplementation $\times$ sampling time $(\mathrm{D} \times \mathrm{T})$. An individual animal was the experimental unit. Data are presented as means and standard errors of groups. Differences were tested by the Scheffé test and considered significant for at least $p<0.05$.

\section{Results}

\section{Productive performance}

In Table 1, the average values of the BW, ADG, milk consumption and milk conversion index of lambs are shown. The final BW (42 d) of the HVB group lambs was higher $(p<0.05)$ than in the $\mathrm{CON}$ group. During the whole experimental period, the ADG values were higher $(P<0.01)$ in the LVB and HVB groups than in the CON group.

In particular, the values of the weight gains in the CON group were lower $(p<0.05)$ than those observed in the HVB group during the first trial period (0-14 d), and the differences also involved the LVB group in the second period (28-42 d). The ADG of lambs was significantly $(p<0.05)$ affected by the effect of time only in the LVB and HVB groups. Average daily milk consumption, calculated over the entire trial, was higher $(p<0.05)$ in the HVB group compared with the CON group, becoming significantly $(p<0.05)$ higher in the last trial period $(28-42 \mathrm{~d})$.

The milk conversion index was not affected by the experimental dietary supplementation. 
Table 1. Body weight, daily gains, milk consumptions and milk conversion index in suckling lambs

\begin{tabular}{|c|c|c|c|c|c|c|c|}
\hline \multirow{2}{*}{ Item } & \multicolumn{3}{|c|}{ Experimental group ${ }^{\dagger}$} & \multirow{2}{*}{ SEM } & \multicolumn{3}{|c|}{$\underline{P \text {-value }}{ }^{\ddagger}$} \\
\hline & $\mathrm{CON}$ & LVB & HVB & & $\mathrm{D}$ & $T$ & $\mathrm{D} \times \mathrm{T}$ \\
\hline Lambs, no. & 8 & 8 & 8 & & & & \\
\hline \multicolumn{8}{|l|}{ Body weight, kg } \\
\hline $0 d$ & 5.11 & 4.90 & 5.24 & 0.09 & 0.187 & & \\
\hline $14 d$ & 7.75 & 7.78 & 8.38 & 0.14 & 0.232 & & \\
\hline $28 d$ & 10.70 & 10.73 & 11.47 & 0.17 & 0.428 & & \\
\hline $42 d$ & $13.42^{1}$ & 13.98 & $14.96^{2}$ & 0.22 & 0.008 & 0.007 & 0.011 \\
\hline \multicolumn{8}{|l|}{ Average daily gain, $g \cdot d^{-1}$} \\
\hline $0-14 d$ & $188.6^{1}$ & $205.8^{a}$ & $224.3^{2 a}$ & 5.6 & 0.027 & & \\
\hline $14-28 d$ & 210.8 & 210.6 & 220.7 & 7.7 & 0.285 & & \\
\hline $28-42 d$ & $194.2^{1}$ & $232.1^{2 b}$ & $249.3^{2 b}$ & 8.5 & 0.018 & & \\
\hline whole trial $(0-42 d)$ & $197.6^{1}$ & $216.6^{2}$ & $234.1^{2}$ & 4.1 & 0.001 & 0.021 & 0.258 \\
\hline \multicolumn{8}{|l|}{ Milk consumption, $g \cdot d^{-1}$} \\
\hline $0-14 d$ & 944.2 & 958.5 & 1054.9 & 22.9 & & & \\
\hline $14-28 d$ & 979.1 & 948.2 & 997.3 & 29.1 & & & \\
\hline $28-42 d$ & $934.3^{1}$ & 1023.1 & $1121.4^{2}$ & 34.1 & & & \\
\hline whole trial $(0-42 \mathrm{~d})$ & $952.6^{1}$ & 976.6 & $1057.9^{2}$ & 15.8 & 0.032 & 0.523 & 0.456 \\
\hline \multicolumn{8}{|c|}{ Milk conversion index $\mathrm{kg}$ of milk $\cdot \mathrm{kg}^{-1}$ weight gain } \\
\hline $0-14 d$ & 4.98 & 4.66 & 4.69 & 0.17 & & & \\
\hline $14-28 d$ & 4.64 & 4.50 & 4.52 & 0.13 & & & \\
\hline $28-42 d$ & 4.81 & 4.41 & 4.48 & 0.05 & & & \\
\hline whole trial $(0-42 \mathrm{~d})$ & 4.81 & 4.52 & 4.55 & 0.10 & 0.275 & 0.227 & 0.111 \\
\hline
\end{tabular}

${ }^{\dagger}$ CON - control diet; LVB - $2.5 \mathrm{mg}$ verbascoside per animal per day ${ }^{-1} ; \mathrm{HVB}-5.0 \mathrm{mg}$ verbascoside per animal per day ${ }^{-1} ;{ }^{\ddagger} \mathrm{D}-$ fixed effect of dietary supplementation; $\mathrm{T}-$ fixed effect of time; $\mathrm{D} \times \mathrm{T}$ - interaction dietary supplementation $\mathrm{x}$ time; ${ }^{1,2}$ within a row, means without a common superscript differ $(p<0.05)$; a,b within a column, means without a common superscript differ $(p<0.05)$

Table 2. Blood parameters of lipid profile in suckling lambs

\begin{tabular}{|c|c|c|c|c|c|c|c|}
\hline \multirow{2}{*}{ Item } & \multicolumn{3}{|c|}{ Experimental group $^{\dagger}$} & \multirow{2}{*}{ SEM } & \multicolumn{3}{|c|}{ P-value ${ }^{\ddagger}$} \\
\hline & $\overline{\mathrm{CON}}$ & LVB & HVB & & $\bar{D}$ & $T$ & $\mathrm{D} \times \mathrm{T}$ \\
\hline Lambs, no. & 8 & 8 & 8 & & & & \\
\hline \multicolumn{8}{|c|}{ Triglycerides, $\mathrm{mmol} \cdot \mathrm{I}^{-1}$} \\
\hline $0 \mathrm{~d}$ & 0.24 & $0.25^{\mathrm{a}}$ & $0.25^{\mathrm{a}}$ & 0.01 & & & \\
\hline $21 d$ & $0.25^{1}$ & $0.24^{1 a}$ & $0.20^{2 b}$ & 0.01 & & & \\
\hline $42 d$ & $0.26^{1}$ & $0.22^{2 b}$ & $0.17^{3 \mathrm{c}}$ & 0.01 & 0.035 & 0.025 & 0.001 \\
\hline
\end{tabular}

Total cholesterol, $\mathrm{mmol} \cdot \mathrm{l}^{-1}$

\begin{tabular}{|c|c|c|c|c|c|c|c|}
\hline $0 \mathrm{~d}$ & 1.91 & 1.93 & $1.93^{\mathrm{a}}$ & 0.02 & & & \\
\hline $21 \mathrm{~d}$ & 1.89 & 1.87 & 1.88 & 0.03 & & & \\
\hline $42 d$ & 1.92 & 1.86 & $1.85^{b}$ & 0.02 & 0.313 & 0.041 & 0.107 \\
\hline
\end{tabular}

$\mathrm{HDL}$ cholesterol, $\mathrm{mmol} \cdot \mathrm{l}^{-1}$

$\begin{array}{rlllllll}0 \mathrm{~d} & 0.78 & 0.79^{\mathrm{a}} & 0.78^{\mathrm{a}} & 0.01 & & & \\ 21 \mathrm{~d} & 0.76^{1} & 0.86^{2 b} & 0.87^{2 b} & 0.01 & & & \\ 42 \mathrm{~d} & 0.77^{1} & 0.91^{2 b} & 0.92^{2 b} & 0.07 & 0.031 & 0.008 & 0.039\end{array}$

$\mathrm{LDL}$ cholesterol, $\mathrm{mmol} \cdot \mathrm{r}^{-1}$

\begin{tabular}{rlllllll}
$0 \mathrm{~d}$ & 1.02 & $1.02^{\mathrm{a}}$ & $1.04^{\mathrm{a}}$ & 0.09 & & & \\
$21 \mathrm{~d}$ & 1.01 & 0.90 & 0.92 & 0.03 & & & \\
$42 \mathrm{~d}$ & $1.03^{1}$ & $0.86^{2 \mathrm{~b}}$ & $0.85^{2 \mathrm{~b}}$ & 0.03 & 0.192 & 0.030 & 0.213 \\
\hline
\end{tabular}

${ }^{\dagger}$ CON - control diet; LVB - 2.5 mg verbascoside per animal per day ${ }^{-1}$; HVB - 5.0 mg verbascoside per animal per day ${ }^{-1} ;{ }^{\ddagger} D-$ fixed effect of dietary supplementation; $T$ - fixed effect of time; $D \times T$ - interaction dietary supplementation $x$ time; ${ }^{-1,2,3}$ within a row, means without a common superscript differ $(p<0.05)$; a,b,c within a column, means without a common superscript differ $(p<0.05)$ 


\section{Blood parameters}

In Table 2, the values of the blood metabolites related to the lipid profile of lambs are reported. Serum concentrations of triglycerides and HDL-C were affected by the dietary treatment with VB $(p<0.05)$.

Triglycerides were lower in the HVB group than in the CON group at 21 and $42 \mathrm{~d}$. In contrast, the LVB group showed a reduction in triglycerides compared with the CON group only on day 42. Moreover, on day 42, the levels of triglycerides in the LVB group were significantly higher than in the HVB group. A time effect $(p<0.05)$ on serum triglycerides was observed in lambs given dietary supplementation, with lower values at the end of the trial in comparison with the initial values. The CON group did not show appreciable variations as the trial progressed. Triglycerides showed a significant interaction between treatment with verbascoside and duration of administration $(P<0.01)$ leading, during the trial, to sensitive changes in blood parameters as the duration of administration increased.

Total cholesterol was not statistically affected by the dietary supplementation. In the HVB group, a time effect was observed with a significant $(p<0.05)$ decrease in total cholesterol ( $0 \mathrm{~d}$ vs $42 \mathrm{~d})$.

Supplementation with verbascoside significantly $(p<0.05)$ increased HDL-C. In both the LVB and HVB groups, the values of HDL cholesterol increased $(P<0.01)$ from the beginning to the end of the trial. The CON group did not show appreciable variations during the trial. Also, a significant $(p<0.05)$ relationship between verbascoside treatment and duration of supplementation was observed.

LDL-C was not significantly affected by dietary supplementation, although in the LVB and HVB groups, its values drastically decreased $(p<0.05)$ from 0 to $42 \mathrm{~d}$, while the CON group did not show any variation.

In Table 3, the values of the tested haemochromocytometric parameters are reported: RBC, WBC, HGB, HCT, MCV, MCH, MCHC and PLT, as well as the serum concentrations of glucose, total proteins, albumin, urea, creatinine, magnesium, chlorine, sodium, potassium and bilirubin. Data in Table 3, except bilirubin, were synthesized by reporting only the values obtained from the average of the samples taken on days 0,21 and 42 because the experimental treatment did not produce any statistical differences. On day 42, the blood levels of bilirubin were lower in the HVB group than in the CON group. Also, the experimental HVB group showed a significant reduction $(p<0.05)$ in values from the beginning to the end of the test. In contrast, no significant differences were found in the CON group in the same period of time.

The administration of VB significantly affected the plasma markers of oxidative status (Table 4).

The dietary treatment reduced the values of ROMs $(P<0.01)$, which was already observed at mid-trial $(21 \mathrm{~d})$ and was confirmed on $42 \mathrm{~d}(223.87$ and 162.97 vs $421.86 \mathrm{U} \cdot \mathrm{Carr}^{-1}$, respectively). Regarding the variability of ROMs during the trial, we found an increase $(P<0.01)$ in the values in the CON group compared with a decrease in the HVB group, whereas the values remained unchanged in the LVB group.

The dietary supplementation with VB led to a reduction $(p<0.05)$ in TBARS. At the end of the trial, the LVB and HVB groups showed lower values of TBARS than the CON group. A significant time effect was found; during the trial TBARS values decreased $(p<0.05)$ in the LVB and HVB groups, respectively, but remained unchanged in the CON group.

The plasma levels of vitamin E were significantly affected $(P<0.01)$ by the experimental treatment. In the HVB group, vitamin $\mathrm{E}$ was higher $(P<0.01)$ than in the CON and LVB groups after 21 days of the trial. The values registered on day 42 confirmed the higher levels of vitamin $\mathrm{E}$ in the HVB group than in the LVB and CON groups (12.837 vs 8.007 and $1.439 \mu \mathrm{mol} \cdot 1^{-1}$, respectively) and a significant increase in those levels between CON and LVB was found. Moreover, in the LVB and HVB groups, a time effect on the values of vitamin $\mathrm{E}$ was shown, with a significant increase $(P<0.01)$ from the beginning to the end of the trial, while in the $\mathrm{CON}$ group it remained unchanged over the same period of time.

The plasma concentration of vitamin A was affected $(p<0.05)$ by the dietary supplementation. In particular, at the end of the trial (42 d), the HVB group showed a higher concentration of vitamin $A$ than the CON and LVB groups $(p<0.05)$. Furthermore, a significant time effect $(p<0.05)$ was observed for vitamin A in the HVB group, with an increase of the values from the beginning to the end of the trial. No statistical differences were recorded in the CON and LVB groups during the same period. All of the parameters in Table 4, except TBARS values, showed a significant interaction between treatment with verbascoside and duration of administration ( $p<0.05)$, indicating that during the trial, sensitive changes occurred in blood parameters as the duration of administration increased. 
Table 3. Some blood parameters in suckling lambs*

\begin{tabular}{|c|c|c|c|c|c|c|c|}
\hline \multirow{2}{*}{ Item } & \multicolumn{3}{|c|}{ Experimental group ${ }^{\dagger}$} & \multirow{2}{*}{ SEM } & \multicolumn{3}{|c|}{$P$-value $\ddagger$} \\
\hline & $\mathrm{CON}$ & LVB & HVB & & $\bar{D}$ & $\mathrm{~T}$ & $\mathrm{D} \times \mathrm{T}$ \\
\hline Lambs, no. & 8 & 8 & 8 & & & & \\
\hline $\mathrm{RBC}, \times 10^{12} \cdot \mathrm{I}^{-1}$ & 8.79 & 8.89 & 8.90 & 0.14 & 0.184 & 0.191 & 0.167 \\
\hline WBC, $\times 10^{9} \cdot \mathrm{I}^{-1}$ & 8.90 & 8.67 & 8.69 & 0.09 & 0.210 & 0.813 & 0.808 \\
\hline $\mathrm{HGB}, \mathrm{g} \cdot \mathrm{I}^{-1}$ & 106.2 & 102.4 & 107.0 & 1.24 & 0.478 & 0.775 & 0.170 \\
\hline HCT, \% & 29.49 & 28.96 & 29.32 & 0.85 & 0.185 & 0.112 & 0.895 \\
\hline $\mathrm{MCV}, \mu \mathrm{m}^{3}$ & 33.50 & 33.27 & 33.54 & 0.39 & 0.278 & 0.785 & 0.169 \\
\hline $\mathrm{MCH}, \mathrm{pg}$ & 11.11 & 11.54 & 11.59 & 0.18 & 0.204 & 0.406 & 0.636 \\
\hline $\mathrm{MCHC}, \mathrm{g} \cdot \mathrm{dl}^{-1}$ & 39.61 & 40.99 & 40.90 & 1.26 & 0.685 & 0.531 & 0.433 \\
\hline PLT, x $10^{9} \cdot \mathrm{I}^{-1}$ & 319.50 & 302.05 & 346.33 & 31.82 & 0.208 & 0.167 & 0.275 \\
\hline Albumin, $\mathrm{g} \cdot \mathrm{I}^{-1}$ & 22.20 & 21.90 & 22.50 & 0.21 & 0.063 & 0.654 & 0.710 \\
\hline Urea, $\mathrm{mmol} \cdot \mathrm{I}^{-1}$ & 5.46 & 5.58 & 5.49 & 0.05 & 0.329 & 0.099 & 0.074 \\
\hline Creatinine, $\mu \mathrm{mol} \cdot \mathrm{I}^{-1}$ & 69.84 & 68.20 & 68.07 & 0.44 & 0.351 & 0.215 & 0.343 \\
\hline \multicolumn{8}{|l|}{ Bilirubin, $\mu \mathrm{mol} \cdot \mathrm{I}^{-1}$} \\
\hline $0 \mathrm{~d}$ & 6.39 & 6.48 & $6.53^{a}$ & 0.11 & & & \\
\hline $21 \mathrm{~d}$ & 6.50 & 6.21 & 6.11 & 0.22 & & & \\
\hline $42 d$ & $6.57^{1}$ & 5.83 & $5.70^{2 b}$ & 0.26 & 0.101 & 0.035 & 0.078 \\
\hline
\end{tabular}

* all data reported, excluding those related to bilirubin, were obtained from average of the samples taken at $0 \mathrm{~d}, 21 \mathrm{~d}$ and $42 \mathrm{~d} ;{ }^{\dagger}$ CON - control diet; LVB - $2.5 \mathrm{mg}$ verbascoside per animal per day ${ }^{-1} ; \mathrm{HVB}-5.0 \mathrm{mg}$ verbascoside per animal per day ${ }^{-1} ;$; D - fixed effect of dietary supplementation; $\mathrm{T}$ - fixed effect of time; D x T - interaction dietary supplementation $x$ time; ${ }^{1,2}$ within a row, means without a common superscript differ $(p<0.05)$; a,b within a column, means without a common superscript differ $(p<0.05)$; RBC - red blood cells; WBC - white blood cells; HGB - haemoglobin; HCT - haematocrit; MCV - mean corpuscular volume; $\mathrm{MCH}$ - mean corpuscular haemoglobin; MCHC - mean corpuscular haemoglobin concentration; PLT - platelets

Table 4. Plasma oxidative status in suckling lambs

\begin{tabular}{|c|c|c|c|c|c|c|c|}
\hline \multirow{2}{*}{ Item } & \multicolumn{3}{|c|}{ Experimental group ${ }^{\dagger}$} & \multirow{2}{*}{ SEM } & \multicolumn{3}{|c|}{$P$-value ${ }^{\ddagger}$} \\
\hline & $\mathrm{CON}$ & LVB & HVB & & $\mathrm{D}$ & $T$ & $\mathrm{D} \times \mathrm{T}$ \\
\hline Lambs, no. & 8 & 8 & 8 & & & & \\
\hline \multicolumn{8}{|c|}{ ROMs, U $\cdot$ Carr $^{-1}$} \\
\hline $0 d$ & $214.38^{a}$ & 215.61 & $212.21^{\mathrm{a}}$ & 6.37 & & & \\
\hline $21 d$ & $362.80^{1 b}$ & $224.12^{2}$ & $220.44^{2 a}$ & 14.80 & & & \\
\hline $42 d$ & $421.86^{1 b}$ & $223.87^{2}$ & $162.97^{3 b}$ & 25.11 & 0.006 & 0.005 & 0.017 \\
\hline \multicolumn{8}{|c|}{ TBARS, $\mu \mathrm{mol} \cdot \mathrm{I}^{-1}$} \\
\hline $0 d$ & 0.242 & $0.300^{\mathrm{a}}$ & $0.250^{\mathrm{a}}$ & 0.020 & & & \\
\hline $21 d$ & 0.230 & $0.157^{b}$ & 0.218 & 0.027 & & & \\
\hline $42 d$ & $0.233^{1}$ & $0.136^{2 b}$ & $0.110^{2 b}$ & 0.013 & 0.022 & 0.032 & 0.182 \\
\hline \multicolumn{8}{|c|}{ Vitamin $E, \mu \mathrm{mol} \cdot \mathrm{I}^{-1}$} \\
\hline $0 d$ & 0.726 & $1.092^{\mathrm{a}}$ & $0.778^{a}$ & 0.110 & & & \\
\hline $21 \mathrm{~d}$ & $0.524^{1}$ & $0.801^{1 \mathrm{a}}$ & $6.575^{2 b}$ & 0.835 & & & \\
\hline $42 d$ & $1.439^{1}$ & $8.007^{2 b}$ & $12.837^{3 c}$ & 1.257 & 0.003 & 0.031 & 0.047 \\
\hline \multicolumn{8}{|c|}{ Vitamin $A, \mu \mathrm{mol} \cdot \mathrm{I}^{-1}$} \\
\hline $0 d$ & 0.057 & 0.058 & $0.058^{a}$ & 0.003 & & & \\
\hline $21 \mathrm{~d}$ & 0.061 & 0.070 & $0.085^{b}$ & 0.007 & & & \\
\hline $42 d$ & $0.061^{1}$ & $0.073^{1}$ & $0.132^{2 c}$ & 0.011 & 0.008 & 0.042 & 0.033 \\
\hline
\end{tabular}

${ }^{\dagger}$ CON - control diet; LVB - 2.5 mg verbascoside per animal per day ${ }^{-1}$; HVB - 5.0 mg verbascoside per animal per day ${ }^{-1} ;$; D - fixed effect of dietary supplementation; $T$ - fixed effect of time; $D \times T$ - interaction dietary supplementation; $T$ - fixed effect of time; $D \times T$ - interaction dietary supplementation $\mathrm{x}$ time; ${ }^{1,2,3}$ within a row, means without a common superscript differ $(p<0.05)$; $a, b, c$ within a column, means without a common superscript differ $(p<0.05)$ 


\section{Discussion}

\section{Productive performance}

The improvement of weight gain in LVB and HVB suckling lambs could be ascribed to the significant improvements of the blood lipid profile characterized by reduction of ROMs and TBARS values, and an increase in vitamin $\mathrm{A}$ and $\mathrm{E}$ levels. This could have had a positive effect on the lambs' wellbeing and growth due to a stronger suckling stimulus and increased milk consumption.

Bampidis et al. (2005) observed improvements in the growth of experimental lambs fed a garlicbased feed supplement, due to the reduction of undesirable bacterial microflora, with improvement of nutrient absorption.

In an experiment carried out on fattening lambs that consumed mixed feed with a blend of essential oil compounds having antioxidant activity, Ozdogan et al. (2011) showed a slight improvement in BW and ADG, which could likely be due to the modification of rumen volatile fatty acid production by increasing the acetate-to-propionate ratio, inhibiting deamination, and the direct inhibition of methane production (Busquet et al., 2006; Castillejos et al., 2007).

Corino et al. (2007b) conducted a similar study on piglets in post-weaning; piglets were fed with a concentrate that was supplemented with two levels of VB, and the authors found considerable growth improvement in the subjects that were fed the highest level of VB. The beneficial effect of phenols and polyphenols can be ascribed, according to some authors (Giannenas et al., 2003; ArcilaLozano et al., 2004; Bozin et al., 2006), to the antimicrobial and antifungal activity inherent in phenolic compounds. Other authors (Esposito et al., 2010; Rossi et al., 2011) have attributed that effect to the anti-inflammatory and immunomodulating activity of phenol compounds.

\section{Blood parameters}

All of the values of the blood metabolites registered in this study were in the normal ranges for this species (Casamassima et al., 1997; Bornez et al., 2009).

The administration of VB (LVB and HVB groups) produced a general improvement in the lipid profile in lambs; this finding was highlighted by a significant decrease in triglycerides and an increase in HDL-C.

The dietary effect on the increase of plasma HDL-C concentration may be ascribed to the effect of such phenylpropanoid glycosides as verbascoside (Carrera-Quintanar et al., 2010) acting as natural ligands of nuclear hormone receptors, peroxisomeproliferator-activated receptors (PPARs) that are involved in lipid and sugar metabolism (Goto et al., 2010; Norata et al., 2003), determining the activation of PPAR $\alpha$ receptors with the effect of modulating, on the hepatic level, the expression of key proteins involved in the metabolism of highdensity lipoproteins such as both apolipoprotein A-I (Apo A-I) and apolipoprotein A-II (Apo A-II). Triglycerides would also be involved in the same mechanism of activation of PPAR $\alpha$; thus, this activation would induce the expression of lipoprotein lipase in peripheral tissues and induce an increase in lipolysis that would translate into a decrease in circulating triglycerides and very-lowdensity lipoproteins.

Our results agree with those of other authors on different species. Improvement of lipid profiles was observed in our earlier work on Italian hares (Lepus corsicanus), rabbits, and dairy ewes intensively reared and fed diets supplemented with water-soluble extracts of Verbenaceae (Lippia spp.) leaves (Casamassima et al., 2011, 2012; Palazzo et al., 2011). In particular, a decrease of total cholesterol and triglycerides and an increase of HDL-C was found. In piglets, Corino et al. (2007a) observed that dietary supplementation with VB significantly reduced serum LDL-C levels with lower values in high-verbascoside-fed piglets.

The lower bilirubin content observed in the HVB at the end of the trial than in the CON and LVB groups may be due to the antioxidant activity of polyphenols, which could inhibit the biochemical mechanisms responsible for the formation of bilirubin. In rabbits that ingested increasing $(0,15$ and $30 \mu \mathrm{g} \cdot \mathrm{kg}^{-1} \mathrm{BW}$ ) doses of aflatoxin B1 every day, Yousef et al. (2003) observed a decrease in bilirubin due to the use of antioxidant substances, such as ascorbic acid, in their diet.

In the present study, dietary supplementation with VB resulted in an improvement in the plasma oxidative status as observed in our earlier works (Casamassima et al., 2011, 2012; Palazzo et al., 2011). This result might be attributed to the ability of polyphenols to neutralize free-radical production at the stage of propagation of the chain reaction (Funes et al., 2009) or to inhibit the activity of prooxidant enzymes responsible for their production, thus protecting both LDL lipids and the $\alpha$-tocopherol of LDL from the attack of radicals (Cos et al., 2002), and promoting regeneration of the radical forms of $\alpha$-tocopherol (Zhou et al., 2005). 
In our studies carried out to assess the physiological effects of dietary supplements with antioxidant activity (Casamassima et al., 2011, 2012; Palazzo et al., 2011), a significant decrease of plasma levels of ROMs and TBARS was observed. Also $\mathrm{Li}$ et al. (1999) reported similar results in a study on skeletal muscles of rats that were subjected to effort. Corino et al. (2007b) fed weaned piglets with a concentrate supplemented with VB and a significant decrease in the ROMs concentration in the plasmawasfound.Inrabbits, Liuetal.(2003)observed a decrease in TBARS. In animals fed a verbascoside-based dietary supplement, the increase of plasma vitamins A and E could be due to the ability of phenylpropanoid glycoside to improve and protect the endogenous antioxidant system by better control of oxidative metabolism and the induction of antioxidant activity enzymes (Liao and Yin, 2000). Similarly to what we observed in the present study, the increase in plasma levels of vitamins $\mathrm{A}$ and $\mathrm{E}$, apart from being stimulated by the use of antioxidants, was also affected by the supplementation of these vitamins in the diet (Corino et al., 1999; Oriani et al., 2001).

\section{Conclusions}

Dietary supplementation with verbascoside (VB) at the highest dose produced a significant improvement in averge daily gain and milk consumption. No influence was observed, however, on the milk conversion index. The administration of VB showed a significant improvement of the blood lipid profile, highlighted by a decrease in triglycerides and an increase in high-density lipoprotein cholesterol in the low-verbascoside (LVB) and high-verbascoside (HVB) lambs. Even if the groups demonstrated a decrease in values, total cholesterol and low-density lipoprotein cholesterol (LDL-C) did not differentiate among the compared groups, although the LVB and HVB groups showed a significant decrease in LDL-C at the end of the trial.

The supplementation of VB improved the plasma oxidative status in suckling lambs by affecting homoeostatic stability that determined a significant decrease in the concentrations of reactive oxygen metabolites and thiobarbituric acid reactive substances and a marked increase in serum concentrations of vitamins $\mathrm{E}$ and $\mathrm{A}$. The obtained results show that the use of the phenylpropanoid glycoside, verbascoside, led to an improvement in some production and blood parameters in suckling lambs.

\section{References}

Akbay P., Calis I., Ündeger Ü., Basaran N., Basaran A.A., 2002. In vitro immunomodulatory activity of verbascoside from Nepeta ucrainica L. Phytother. Res. 16, 593-595

Arcila-Lozano C.C., Loarca-Piña G., Lecona-Uribe S., Gonzáles de Mejía E., 2004. Oregano: Properties, composition and biological activity. Arch. Latinoamer. Nutr. 54, 100-111

Bampidis V.A., Christodoulou V., Christaki E., Florou-Paneri P., Spais A.B., 2005. Effect of dietary garlic bulb and garlic husk supplementation on performance and carcass characteristics of growing lambs. Anim. Feed Sci. Tech. 121, 273-283

Bórnez R., Linares M.B., Vergara H., 2009. Haematological, hormonal and biochemical blood parameters in lamb: effect of age and blood sampling time. Livest. Sci. 121, 200-206

Bozin B., Mimica-Dukic N., Simin N., Anackov G., 2006. Characterization of the volatile composition of essential oils of some lamiaceae spices and the antimicrobial and activities of the entire oils. J. Agr. Food Chem. 8, 1822-1828

Busquet M., Calsamiglia S., Ferret A., Kamel C., 2006. Plant extracts affect in vitro rumen microbial fermentation. J. Dairy Sci. 89, $761-771$

Carrera-Quintanar L., Funes L., Viudes E., Tur J., Micol V., Roche E., Pons A., 2010. Antioxidant effect of lemon verbena extracts on lymphocytes of university students performing aerobic training program. Scand. J. Med. Sci. Sports. doi: 10.1111/j.1600-0838.2010.01244.x

Casamassima D., Palazzo M., Martemucci G., Vizzarri F., Corino C., 2012. Effects of verbascoside on plasma oxidative status and blood and milk production parameters during the peripartum period in Lacaune ewes. Small Ruminant Res. 105, 1-8

Casamassima D., Sevi A., Petazzi F., Rubino G., 1997. Blood profile in different ovine breed reared in Murgia Bares land (in Italian). Arch. Vet. Ital. 48, 57-66

Casamassima D., Vizzarri F., Palazzo M., Massanyi P., Ondruska L., Corino C., 2011. Effect of the addition of a verbascoside-based food supplement in feed, on some blood parameters and plasma oxidative status in White New Zealand rabbits. In: Proceedings of the $9^{\text {th }}$ International Scientific Conference. Castle Mojmirovce (Slovak Republic)

Castillejos L., Calsamiglia S., Ferret A., Losa R., 2007. Effects of dose and adaptation time of a specific blend of essential oil compounds on rumen fermentation. Anim. Feed Sci. Tech. 132, 186-201

Cesarone M.R., Belcaro G., Caratelli M., Cornelli U., De Sanctis M.T., Incandela L., Barsotti A., Teranova R., Nicolaides A.,,1999. A simple test to monitor oxidative stress. Int. Angiol. 18, $127-130$

Corino C., Cannata S., Musella M., Pastorelli G., Rossi R., 2007a. Influence of verbascoside on lipid profile in weaned piglets. 10th European Nutrition Conference. Ann. Nutr. Metab. 51, Suppl. 1, 270 (Abstr.)

Corino C., Oriani G., Pantaleo L., Pastorelli G., Salvatori G., 1999. Influence of dietary vitamin $E$ supplementation on heavy pig carcass characteristics, meat quality, and vitamin E status. J. Anim. Sci. 77, 1755-1761

Corino C., Rossi R., Musella M., Cannata S., Pastorelli G., 2007b. Growth performance and oxidative status in piglets supplemented with verbascoside and teupolioside. Ital. J. Anim. Sci. 6, 292-294 
Cos P., Rajan P., Vedernikova I., Calomme M., Pieters L., Vlietinck A.J., Augustyns K., Haemers A., Vanden Berghe D., 2002. In vitro antioxidant profile of phenolic acid derivatives. Free Radical Res. 36, 711-716

Deepak M., Handa S.S., 2000. Anti-inflammatory activity and chemical composition of extracts of Verbena officinalis. Phytother. Res. $14,463-465$

Ellis B.E., 1983. Production of hydroxyphenylethanol glycosides in suspension cultures of Syringa vulgaris. Phytochemistry 22, 1941-1943

Esposito E., Dal Toso R., Pressi G., Bramanti P., Meli R., Cuzzocrea S., 2010. Protective effect of verbascoside in activated C6 glioma cells: possible molecular mechanisms. N-S Arch. Pharmacol. 381, 93-105

Esterbauer H., Zollern H., 1989. Methods for determination of aldehydic lipid peroxidation products. Free Radical Biol. Med. 7, 197-203

Funes L., Fernández-Arroyo S., Laporta O., Pons A., Roche E., Segura-Carretero A., Fernández-Gutiérrez A., Micol V., 2009. Correlation between plasma antioxidant capacity and verbascoside levels in rats after oral administration of lemon verbena extract. Food Chem. 117, 589-598

Gao J.J., Igalashi K., Nukina M., 1999. Radical scavenging activity of phenylpropanoid glycosides in Caryopteris incana. Biosci. Biotechnol. Biochem. 63, 983-988

Giannenas I., Florou-Paneri P., Christaki M.E., Botsoglou N.A., Spais A.B., 2003. Effect of dietary supplementation with oregano essential oil on performance of broilers after experimental infection with Eimeria tenella. Arch. Anim. Nutr. 57, 99-106

Goto T., Takahashi N., Hirai S., Kawada T., 2010. Various terpenoids derived from herbal and dietary plants function as PPAR modulators and regulate carbohydrate and lipid metabolism. PPAR Res. 2010:doi:10.1155/2010/483958

Grassmann J., Hippeli S., Dornischa K., Rohnerta U., Beuscherb N., Elstnera EF., 2000. Antioxidant properties of essential oils - possible explanation for their anti-inflammatory effects. Arzneimittel-Forsch. 50, 135-139

Kernan M.R., Amarquaye A., Chen J.L. et al., 1998. Antiviral phenylpropanoid glycosides from the medicinal plant Markhamia lutea. J. Nat. Prod. 61, 564-570

Lee Y., Howard L.R., Villalón B., 1995. Flavonoids and antioxidant activity of fresh pepper Capsicun annuum cultivars. J. Food Sci. 60, 473-476

Li J.X., Xin D., Li H., Lu J.F., Tong C.W., Gao J.N., Chan K.M., 1999. Effect of verbascoside on decreasing concentration of oxygen free radicals and lipid peroxidation in skeletal muscle. Acta Pharm. Sinic. 20, 126-130

Liao K.L., Yin M.C., 2000. Individual and combined antioxidant effects of seven phenolic agents in human erythrocyte membrane ghosts and phosphatidylcholine liposome systems: Importance of the partition coefficient. J. Agr. Food Chem. 48, 2266-2270

Liu M., Li J., Guo H., Lee K., Qin L., Chan K., 2003. The effects of verbascoside on plasma lipid peroxidation level and erythrocyte membrane fluidity during immobilization in rabbits: a time course study. Life Sci. 73, 883-892
Mazzon E., Esposito E., Di Paola R., Riccardi L., Caminiti R., Dal Toso R., Pressi G., Cuzzocrea S., 2009. Effects of verbascoside biotechnologically produced by Syringa vulgaris plant cell cultures in a rodent model of colitis. N-S. Arch. Pharmacol. 380, 79-94

Marzocco S., Piccinelli A.L., Rastrelli L., Mazzon E., Cuzzocrea S., Autore G., 2007. Inhibition of inducible nitric oxide synthase in vitro and in vivo by a water-soluble extract of Wendita calysina leaves. N-S. Arch. Pharmacol. 275, 349-358

Norata G.D., Pellegatta F., Catapano A.L., 2003. "Peroxisome proliferators actived receptors" e patologie cardiovascolari. Ital. Heart J. 4, 8-18

Oriani G., Corino C., Pastorelli G., Pantaleo L., Ritieni A., Salvatori G., 2001. Oxidative status of plasma and muscle in rabbits supplemented with dietary vitamin E. J. Nutr. Biochem. 12, 138-143

Özdoğan M., Önenç S.S., Önenç A., 2011. Fattening performance, blood parameters and slaughter traits of Karya lambs consuming blend of essential oil compounds. Afr. J. Biotechnol. 10, 6663-6669

Palazzo M., Vizzarri F., Cinone M., Corino C., Casamassima D., 2011. Assessment of a natural dietary extract, titrated in phenylpropanoid glycosides, on blood parameters and plasma oxidative status in intensively reared Italian hares (Lepus corsicanus). Animal 5, 844-850

Perucka I., Materska M., 2001. Phenylalanine ammonia-lyase and antioxidant activities of lipophylic fraction of fresh pepper fruits Capsaicum annum L. Innov. Food Sci. Emerg. 2, 189-192

Rossi R., Corino C., Pastorelli G., Durand P., Prost M., 2009. Assessment of antioxidant activity of natural extracts. Ital. J. Anim. Sci. 8, 655-657

Rossi R., Pastorelli G., Corino C., 2011. Influence of dietary plant antioxidant on oxidative status and immune parameters in post weaning piglet. Ital. J. Anim. Sci. 10, 6-7

Sies H., 1991. Oxidative Stress. Academic Press Ltd. Orlando, FL

SPSS, 2010. 18.0 Package program, User's Guide, SPSS Inc. Chicago, IL

Yoshioka M., Matsuo T., Lim K., Tremblay A., Suzuki M., 2000. Effect of capsaicin on abdominal fat and serum free fatty acids in exercise-trained rats. Nutr. Res. 20, 1041-1045

Yousef M.I., Salem M.H., Kamel K.I., Hassan G.A., El-Nouty F.D., 2003. Influence of Ascorbic Acid Supplementation on the hematological and clinical biochemistry parameters of male rabbits exposed to Aflatoxin $B_{1}$. J. Environ. Sci. Health B-Pestic. 38, 193-209

Zhao B., Tham S.-Y.., Lu J., Lai M.H., Lee L.K.H., Moochhala S.M., 2004. Simultaneous determination of vitamins $C, E$ and $\beta$-carotene in human plasma by high-performance liquid chromatography with photodiode-array detection. J. Pharm. Pharmaceut. Sci. 7 (2), 200-204

Zhou B., Wu L.M., Yang L., Liu Z.L., 2005. Evidence for a-tocopherol regeneration reaction of green tea polyphenols in SDS micelles. Free Radical Biol. Med. 38, 78-84 